This is post-print version of the article. To cite this article: Sorada Tapsuwan \& Maksym Polyakov (2015) Correctly Specifying Environmental Assets in Spatial Hedonic Pricing Models, Society \& Natural Resources 29:233-249 http://dx.doi.org/10.1080/08941920.2015.1024808

\title{
Correctly specifying environmental assets in spatial hedonic models
}

\author{
Sorada Tapsuwan ${ }^{a}$ and Maksym Polyakov ${ }^{b}$ \\ ${ }^{a}$ CSIRO Land \& Water Flagship, Wembley, Western Australia, Australia, and School of Agricultural \\ and Resource Economics, University of Western Australia, Crawley, Western Australia, Australia \\ ${ }^{b}$ Centre for Environmental Economics and Policy, School of Agricultural and Resource Economics, \\ University of Western Australia, Crawley, Western Australia, Australia
}

\begin{abstract}
In hedonic pricing models, researchers attempt to capture the marginal benefits of environmental assets using various classifications to differentiate them, such as natural parks versus playground parks. This improves the accuracy of the estimation but the trade off is the increased time and cost of data acquisition. Emphasis is given to classifying the environmental asset of interest as best as possible while other assets of 'minor' interest are given less importance. Often, conventional techniques are applied to estimate the benefits of assets of 'minor' interest, such as estimating distance to the nearest site only, or applying a weighted distance measure to all sites. In this study we demonstrate the errors associated with using the conventional techniques to deal with poor data quality. By assuming homogeneity of all sites, researchers inadvertently place too much value on some assets and too little value on others, which could result in misleading policy recommendations.
\end{abstract} Keywords: valuation, natural parks, multiple sites, weighted distance, Australia

\section{Introduction}

The hedonic property price (HPP) approach is commonly used in the valuation of natural resources to estimate the marginal benefit of proximity to a specific place, for example, a nature conservation park, that has high social and environmental values. Past HPP studies either value one site of interest, such as a popular natural park, or one specific type of environmental asset, such as urban wetlands. Often, when one type of environmental asset is valued, there are multiple sites of that asset in the study area. In this situation, researchers commonly estimate the proximity variable based on the distance to the nearest site (see e.g., Hatton MacDonald et al. 2010; Sander et al. 2010; 
Tapsuwan et al. 2009; Mansfield et al. 2005 ) rather than the distance to all the sites. Bark et al. (2011) provided justification that the nearest site should be used because one can hypothesize that a home owner would be primarily influenced by the characteristics of the environmental site that is closest to them. Alternatively, to take into account the amenity value of relatively homogeneous (multiple) patches of forests, Powe et al. (1997) constructed a forest access index, which is the sum of the area of forest patches divided by the squared distance between the property and the forest patches. This method accounts for the fact that each site has an effect on property price. However, one common thread between these two methods is that strong assumptions are being made that buyers are indifferent between any of these sites as long as they follow the same geographical information databases category. In reality, two environmental assets of the same type can be regarded very differently by home buyers, and can contribute significantly differing values to property price.

Recently, other studies have found that generalizing a single asset with multiple characteristics can result in misleading policy implications. For example, Ham et al. (2012) cautioned against the method of considering forest based land uses as one homogenous good. They argued that specifying a forest area as one homogenous good (rather than separating them into multiple areas based on land use characteristics) overstates the benefits for homes nearby. Thus, Ham and colleagues separated the forest area into two major sections: areas for recreational activities and areas with noise intensive activities. Their results indicated that home buyers find areas with noise intensive activities less desirable and that such negative characteristics would not have been identified if the forests were modelled as one homogenous good. Similarly, Tapsuwan et al. (2012) assigned a recreational index value to nature conservation areas in order to separate high from low recreational value forested areas. Their findings suggest that including recreational quality indices of nature parks better captures how home buyers value environmental amenities. Likewise, Tyrväinen et al. (2007) estimated the benefits of being in close proximity to urban forests but divided their urban forests into wooded recreation area and forested park. They found that only distance to the forested park was significant in their model. Similarly, Hatton MacDonald et al. (2010) found that the effect of proximity to nature reserves on sales price varies with the type of use (e.g. hiking, sporting and playground). Examples such as these suggest that what one may consider a single homogenous good is in fact a combination of multiple goods with different benefits. This needs to be identified in order to correctly estimate the marginal value of proximity to environmental locations.

Unfortunately, such detailed classification of environmental assets often does not exist, or if it does exist, can be difficult to access, and costly to acquire. When researchers have to work within these constraints, the outcome is often that the environmental asset of interest, the one they are trying to value, is well classified. Meanwhile, other environmental assets that are not the main research interest are assumed to follow the characteristics as identified by geographical information systems (GIS). Mahan et al. (2000), for example, estimated the value of urban wetlands on property price. They hypothesized that wetlands have heterogeneous characteristics and therefore divided their wetlands into eight categories (e.g. open water linear wetland, forest linear wetland, emergent 
vegetation linear wetland, etc). They also included distance variables for streams, rivers, lakes, and parks but no additional classifications were given for these assets. Their results indicate that proximity to four wetland types, streams and lakes were found to have a statistically significant relationship with property price, but distance to the nearest park and river were not statistically significant. Parks and rivers may genuinely not have an effect on sales price. However, there is a possibility that some types of parks and rivers do affect sales price, but their effects could not be teased out due to the way they were classified in the model.

When data on site characteristics are not available, one solution is to consider each site as a separate asset and model them separately in the HPP model. By modelling these sites as separate variables, one can deal with site heterogeneity without having to search for any classification. In this paper, we demonstrate the importance of correctly specifying environmental assets in a HPP model and propose a method that is suitable for dealing with poor quality data. We estimated the effect of proximity to three forested nature conservation areas that have been bannered under the term key environmental assets (KEAs) in the Murray-Darling Basin (MDB), Australia, on property price. We first modelled these KEAs as a single variable, using the nearest site and the weighted distance methods. We then modelled them as three separate independent variables. Results from our model comparison suggest that the parameter estimates and the significance level for the effect of these environmental assets differ between the three models. To confirm the robustness of our findings, we performed the same model comparison method on two additional environmental assets that were classified in GIS as national parks (NPs). Results from the analysis of NPs are consistent with the findings from the KEA model. We therefore argue the importance of distinguishing the type of environmental asset in HPP models, when information on site characteristics is limited, regardless of whether the environmental asset is the one of interest to the research or not. The intuition behind this argument is that home buyers do not always perceive environmental characteristics the same way technicians or environmental experts do. Additionally, we estimate the marginal implicit price (MIP) of proximity to the three KEAs. We demonstrate that the MIP significantly differs when the three KEAs are modelled as a single variable and when modelled as separate variables. The MIP values for NPs also produce the same findings.

The following section describes the study area which is the MDB. Section 3 discusses the HPP model specification and the data sets used in the analysis. The results are presented in Section 4 and Section 5 concludes the paper and discusses the implications of the findings.

\section{Study site}

The MDB provides a good case study example to demonstrate the variation in MIP depending on how the sites are specified: as a single asset or as separate assets. The MDB (see Figure 1 ) has many environmental amenities comprising of forests, rivers, wetlands, lakes and floodplains that provide habitat for plants and animals, i.e. 440,000 km of rivers and 30,000 wetlands (MDBA 2011). The Millennium Drought, which lasted for around 10 years (1997-2009), brought about the need to 
decide which environmental assets were to receive water flows (i.e. diverting river water into high priority wetlands rather than low priority ones). A number of sites have been identified by the Murray-Darling Basin Authority (MDBA) as KEAs and are considered areas of significance as they have high social and ecological values, and support water dependent ecosystems that are rare, unique, or threatened (MDBA 2011). The three environmental sites that have been identified by the MDBA as KEAs are the Barmah-Millewa Forest (BMF), the Gunbower-Koondrook-Perricoota Forest (GKPF), and the Lower Goulburn Floodplain (LGFP).

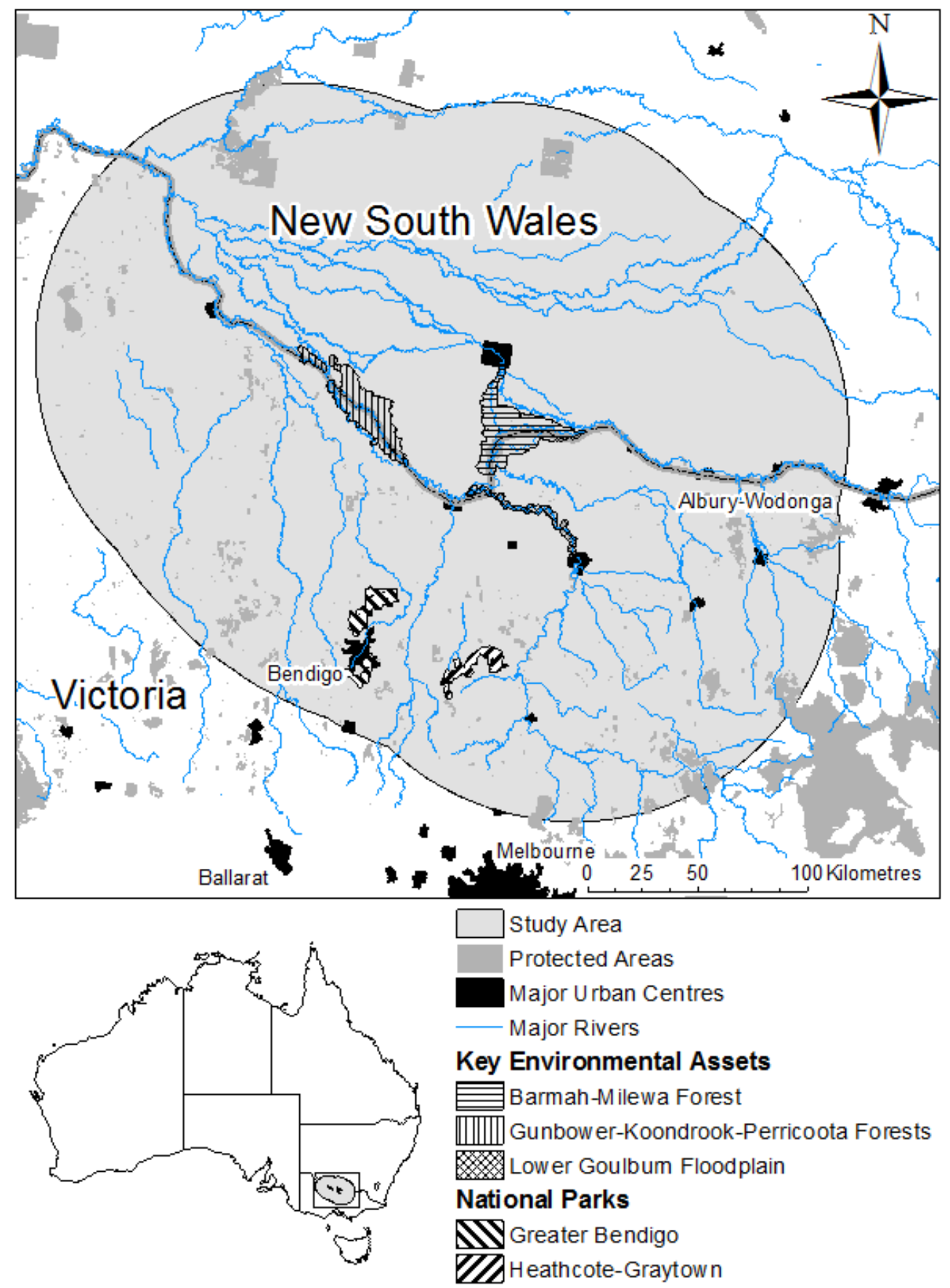

Figure 1. Location of the Study Area 
The Barmah-Millewa Forest is approximately 67,570 ha and straddles the New South Wales and Victoria State border. It is a Ramsar wetland containing the largest area of river red gum forest and woodland. The BMF has high recreational value because of its forest and river environment where visitors can go bushwalking, bird watching, fishing, and camping (Murray-Darling Basin Commission 2005b). The GKPF covers an area of around 50,000 ha. It is Australia's second largest river red gum forest and is an important breeding ground for waterbirds and native fish (MDBA 2012). It is one of the iconic sites in the MDB. The creeks and wetlands of the GKPF are popular for fishing, camping and hunting (Murray-Darling Basin Commission 2005a). The LGFP is part of the Goulburn River system. During the Millennium Drought the Goulburn River suffered a decade of below average rainfall resulting in well below average stream flows, loss of bank vegetation, increased sedimentation of the streambed, increased water turbidity and loss of habitat for juvenile trout (DEPI 2010).

\section{Methodology}

Unlike private goods, the demand for environmental amenities, such as environmental water flow, cannot be directly observed in the market. However, the demand for environmental amenities can be inferred from market transactions of private goods, such as the sales of properties (Freeman 2003).

\subsection{General model specification}

Using the theoretical framework for residential property markets proposed by (Rosen 1974) and expanded by (Freeman 1974), a property can be considered as a multi-attribute good that consists of structural attributes (e.g. bedrooms, bathrooms), neighbourhood attributes (e.g. distance to town center) and environmental attributes (e.g. distance to environmental amenities, area of environmental amenities and quality of environmental amenities). Using this theoretical framework, we can estimate the value of environmental amenities that is capitalised in property prices. The general specification for the hedonic property price regression is

$P_{i}=f\left(S_{i}, N_{i}, E_{i}, T_{i}\right)$

where

$P_{i} \quad$ is the CPI adjusted selling price (to 2010 value) of property $\mathrm{i}$

$S_{i} \quad$ is a vector of structural attributes of property $\mathrm{i}$

$N_{i} \quad$ is a vector of neighbourhood attributes of property $\mathrm{i}$

$E_{i} \quad$ is a vector of environmental attributes associated with property $\mathrm{i}$

$T_{i} \quad$ is a variable to express the sales date of property i relative to year 2000 
To illustrate the importance of modelling the effect of KEAs as separate variables versus one variable, we develop three models. In the first model, shown in equation (2), the effect of all three KEAs are represented by one variable, which is the distance to the nearest KEA. The same specification applies for the two NP variables, which is $\sum \tau_{k}\left(D_{-} N E A R_{k}\right)_{i}$, where $k$ represents KEAs and NPs.

Model 1: $\mathrm{P}_{\mathrm{i}}=\alpha+\gamma \mathrm{S}_{\mathrm{i}}+\delta \mathrm{N}_{\mathrm{i}}+\sum \tau_{\mathrm{k}}\left(\mathrm{D}_{-} \mathrm{NEAR}_{\mathrm{k}}\right)_{\mathrm{i}}+\phi \mathrm{E}(\mathrm{OTH})_{\mathrm{i}}+\vartheta \mathrm{T}_{\mathrm{i}}$

The second model also considers the effect of three KEAs and NPs as one variable but this effect is represented by the weighted harmonic mean distance to all three KEAs, $\sum \theta_{k}\left(D_{-} W_{E} I G H T_{k}\right)_{i}$, which is similar to the forest access index in (Powe et al. 1997) and calculated as $D_{\text {WEIGHTi }}=$ $\sum_{j=1}^{3} w_{j} / \sum_{j=1}^{3} w_{j} / D_{i j}$, where $w_{j}$ is weight (area) of $j$-th KEA and $D_{i j}$ is the distance between property $i$ and environmental asset $j$, as shown in equation (3). The purpose of having two distance measures for a single KEA variable is to compare whether there are significant differences in the MIP when a weighted distance measure is used rather than distance to the nearest site.

Model 2: $\mathrm{P}_{\mathrm{i}}=\alpha+\gamma \mathrm{S}_{\mathrm{i}}+\delta \mathrm{N}_{\mathrm{i}}+\sum \theta_{\mathrm{k}}\left(\mathrm{D}_{-} \mathrm{WEIGHT}_{\mathrm{k}}\right)_{\mathrm{i}}+\phi \mathrm{E}(\mathrm{OTH})_{\mathrm{i}}+\vartheta \mathrm{T}_{\mathrm{i}}$

The third model assumes that all three KEAs and the two NPs are separate types of assets and are represented by three and two separate independent variables as show in equation (4).

Model 3: $\mathrm{P}_{\mathrm{i}}=\alpha+\gamma \mathrm{S}_{\mathrm{i}}+\delta \mathrm{N}_{\mathrm{i}}+\sum \beta_{\mathrm{j}}\left(\mathrm{D}_{\mathrm{j}}\right)_{\mathrm{i}}+\phi \mathrm{E}(\mathrm{OTH})_{\mathrm{i}}+\vartheta \mathrm{T}_{\mathrm{i}}$

where $D_{j}$ is a vector of distance variables to site $j$, which are the BMF, the GKPF, the LGFP, and the two NPs.

A number of functional forms were considered for each of the hedonic models. Economic theory offers little guidance on functional form but suggests that the selling price of a property is likely to vary non-linearly with some of the attributes of the house or neighbourhood (Taylor 2008). To identify appropriate functional from of the HPP model, we used a series of Box-Cox transformations, which suggested that the HPP model with natural log transformed dependant variable is the most suitable fit for the data. In order to capture non-linearities in the relationship between the natural log of sale prices and the independent variables, we also have log transformed and squared terms for the independent variables.

\subsection{Spatial hedonic model}

Spatial dependencies are common in hedonic models (Conway et al. 2010; Donovan and Butry 2010) due to the fact that property sales data as well as location-specific environmental characteristics 
often exhibit spatial dependency relationships. When the errors of the model are spatially correlated due to unobserved variables or measurement errors in variables related to the location of a property, spatial error relationship occurs:

$P=\alpha+X^{\prime} \beta+\varepsilon$

$\varepsilon=\lambda \mathrm{W} \varepsilon+\mathrm{u}$

where $W$ is $n \times n$ spatial weight matrix, $\lambda$ is the spatial error coefficient and $u$ is an uncorrelated error term. Spatial weight matrix $W$ defines the way in which observational units are believed to be influencing each other (see Taylor 2003; Anselin 1988). Most of the observations in our data set are not immediate neighbours. Among the approaches used to define spatial weight matrix in such cases are inclusion into spatial weight matrix $k$ - nearest neighbours or observations within certain distance. Furthermore, there could be an assumption about the weakening of spatial relationship with distance with the most common assumption being that it decays proportionally to the inverse distance between the observations. Spatial weight matrices are usually row-standardised in order to facilitate interpretation of the coefficients.

For the purpose of testing for the presence of spatial dependencies and estimating spatial model, we need a spatial weight matrix. A contiguity matrix cannot be used because observations in our dataset are not immediate neighbours. We constructed a row-normalised nearest neighbour weight matrix. Following Kovacs et al. (2011), we experimented with 2-, 4-, and 8- nearest neighbour matrices, with 8-nearest neighbour matrix showing better fit (based on the robust LM tests).

When the dependent variable, such as sales price, is affected by the values of dependent variables of the neighbouring observations beyond the shared characteristics of the units of observation, spatial lag relationship occurs. For example, sales price of a property could be affected by the sales prices of properties in the neighbourhood. This contradicts the idea underlying hedonic method that the value of a composite good is determined by its characteristics. However, in reality this takes place when collecting information is costly and potential buyers use comparable sales from previous time periods to determine the value of the property (Maddison, 2009). The spatial lag model is defined as:

$P=\alpha+X^{\prime} \beta+\rho W^{\prime} P+\varepsilon$

where $\rho$ is the spatial lag coefficient.

The presence of spatial dependencies violates assumptions of the classical ordinary least squares (OLS) models and causes bias and inconsistent or inefficient estimates of the MIPs when the OLS method is used (Anselin 1988). Due to simultaneity, spatial error and spatial lag models cannot be estimated using OLS method, therefore maximum likelihood or instrumental variables methods are 
used instead. Furthermore, due to spill-over effects in spatial lag model, the MIPs are inflated (Kim et al. 2003) and should be calculated as

$\frac{\partial \mathrm{P}}{\partial \mathrm{x}_{\mathrm{k}^{\prime}}}=\beta_{\mathrm{k}}[1-\rho \mathrm{W}]^{-1}$

This is not an issue with the spatial error model.

\subsection{Data collection}

Three types of data were collected for this analysis: property sales data, geo-spatial data and town tourism data. A full list of the variables and the descriptive statistics is presented in Table 1.

Table 1. Descriptive statistics.

\begin{tabular}{lrrrr}
\hline Variable & Mean & Std Dev & Min & Max \\
\hline Adjusted sales price, AU\$ & 193,889 & 123,329 & 894 & $10,504,490$ \\
Property area, m2 & 2,635 & 5,319 & 158 & 39,980 \\
Number of bedrooms & 3.08 & 0.58 & 1 & 12 \\
Agricultural land use & 0.08 & 0.26 & 0 & 1 \\
Tourist town & 0.60 & 0.49 & 0 & 1 \\
Population gravity index & 104,945 & 32,101 & 35,419 & 229,581 \\
Distance to town, km & 4.1 & 4.7 & 0.0 & 44.3 \\
Distance to BMF, km & 86.4 & 38.2 & 0.2 & 204.7 \\
Distance to GKPF, km & 101.5 & 44.4 & 0.1 & 205.5 \\
Distance to LGFP, km & 68.5 & 40.2 & 0.2 & 217.0 \\
Distance to nearest KEA, km & 60.9 & 38.7 & 0.1 & 120.5 \\
Weighted distance to BMF,GKPF,LGFP, km & 82.2 & 41.7 & 0.3 & 173.3 \\
Distance to Bendigo NP, km & 73.8 & 58.7 & 0.0 & 227.8 \\
Distance to Heathcote-Graytown NP, km & 72.1 & 43.0 & 0.1 & 247.2 \\
Distance to the Nearest NP, km & 55.8 & 47.5 & 0.0 & 227.8 \\
Weighted distance to NP, km & 66.5 & 53.1 & 0.0 & 232.9 \\
Distance to the nearest river, km & 3.5 & 4.7 & 0.0 & 43.1 \\
Area of nearest conservation area, ha & 4,096 & 13,508 & 0 & 661,125 \\
Distance to nearest conservation area, km & 2.6 & 4.3 & 0.0 & 48.9 \\
Average NDVI 12 month prior to sale & 6.3 & 9,780 & 25,951 & 87,655 \\
Elevation level, m & & 63 & 54 & 255 \\
Trend, years & 2.8 & 1.0 & 11.5 \\
\hline & & & & 0.0 \\
\hline
\end{tabular}




\subsubsection{Property sales data}

To estimate the value of environmental assets we use residential and rural residential properties smaller than 4 ha within the distance of $120 \mathrm{~km}$ from either KEA. Limiting property size to 4 ha or less ensures that large scale commercial farming properties are not included. The rationale for selecting $120 \mathrm{~km}$ distance is that it is approximately within 2 hour drive from an environmental asset, which is appropriate for a day trip. The study area covers $94,000 \mathrm{~km}^{2}$ spanning across the states of Victoria and New South Wales. Property sales data for the State of Victoria was acquired from the Valuer General's Office, while New South Wales data was obtained from RP Data, a private company with extensive data base of property sales information in Australia. Sales data for both states spanned the period of 2001 to 2011 . This data set consists of market sales price, sales date, land area and structural attributes. Due to the different sources of the property sales data, there are some variations in what type of data is available. However, there is a sufficient amount of attributes that the databases share. These attributes include sales price, sales date, number of bedrooms and land area. All sales prices were adjusted using consumer price index at the 2010 price level (Reserve Bank of Australia 2012). To capture the effect of market growth during the study period, we included a continuous trend variable and its squared term. The trend variable starts counting from January 1 , 2001 , and increases by one every year.

\subsubsection{Geospatial data}

Values associated with environmental and neighbourhood attributes, such as distance to the nearest town and size of nature conservation areas, were calculated in ArcGIS. Environmental assets that were considered to effect property price in this study were nature conservation areas, rivers, three KEAs, namely the BMF, the GKPF, and the LGFP, and two NPs (Bendigo NP and Heathcote-Graytown NP). It is hypothesized that close proximity to KEAs, NPs, and the river will add value to property sales price. The effect of nature conservation areas on sales price is captured by a variable that combines proximity to and size of these areas (area is divided by distance). We assume that both proximity and size positively affect sales price. Distances to the nearest entry point into KEAs and NPs were calculated using the ArcGIS Network Analysis extension (ESRI 2010). Euclidean distance from the property centroid to the nearest river, town, and nature conservation areas was calculated using a spatial join operation. The area of an environmental asset was calculated using the ArcGIS calculate geometry operation.

An agricultural land use dummy variable was used to control for price differences between agricultural (i.e. hobby farms) and residential land. In a HPP study of the MDB in South Australian by Tapsuwan et al. (2012), properties with a barn, which is congruent with farmland, lowers property price. Therefore, we hypothesize that agricultural land has relatively lower value than residential 
land. Elevation is a proxy for construction $\operatorname{cost}^{1}$ and premium view (Bark et al. 2011). As such, it is hypothesized to have a positive correlation with sales price. Neighbourhood vegetation greenness has been found to have a positive effect on sales price (see e.g., Bark et al. 2011; Hatton MacDonald et al. 2010; Payton et al. 2008). Payton et al. (2008), for example, examined the effect of greener vegetation (as proxied by the Normalized Difference Vegetation Index - NDVI) on property price in Indianapolis/Marion County and found that greener vegetation surrounding a property has a positive effect on price. NDVI is a measure of vegetation greenness and thickness in the landscape (Bureau of Meteorology 2014). NDVI information are derived from satellite data and captured in GIS maps that show the status of live green vegetation (thickness and greenness) on the landscape. For this study, the scale of NDVI is at the local government area level, and the data is available monthly. For the analysis, we used the average NDVI level 12 months preceding the sales of the property to capture vegetation greenness of the local government area in which the property was sold. The reason for using the average NDVI 12 months prior to sale, rather than the NDVI a few months prior to sale is to capture the greenness level of the landscape without the influence of seasonal fluctuations (Sengupta and Osgood 2003). In this analysis, NDVI is hypothesized to have a positive impact on sales price.

To control for accessibility to urban amenities such as employment, services, and entertainment we use the Population Gravity Index variable (PGI) introduced by Polyakov and Zhang (2008). This index incorporates both distances to populated places such as cities, towns, and size of these populated places reflecting quantity and variety of offered amenities. The PGI is calculated as the sum of the inverse squared distance weighted population of urban centers and localities within a certain radius from the property: $P G I_{i}=\sum_{j=1}^{J_{i}} Q_{j} / D_{i, j}^{2}$ where $P G I_{i}$ is the Population Gravity Index for property $i$, $Q_{j}$ is the population size of the urban center or locality $j$, and $D_{i, j}$ is the Euclidean distance between property $\mathrm{i}$ and the urban center or locality $\mathrm{j}$ in kilometres. We include urban centers and localities within $700 \mathrm{~km}$ radius of the property to take into account the influence of Melbourne, Sydney and Adelaide. Spatial and tabular data on population of urban centers and localities obtained from the Australian Bureau of Statistics website (www.abs.gov.au) were used to calculate a measure of population accessibility for each observation.

\subsubsection{Other data}

A HPP study in South Australia showed that houses near parks with recreational facilities (i.e. catered for tourism) sell for higher prices than houses near parks without recreational facilities (Tapsuwan et al. 2012). In this analysis, we included a variable called 'tourist town' to capture whether proximity to tourist destinations effect sales price (i.e. 'tourist town' $=1$ if nearest town is a

\footnotetext{
${ }^{1}$ The cost of earth moving, land grading and soil stabilization to prevent erosion could add at least $7 \%-20 \%$ to the cost of construction depending on how steep is the slope of the block (source: http://buildingadvisor.com/ and http://www.homedesigndirectory.com.au/).
} 
tourist destination and $=0$ otherwise). We used information on caravan parks and tourist information centers as determinants of a tourist destination ${ }^{2}$. Regional towns without tourist sites generally do not have caravan parks because they do not have enough visitors to support the business. If the nearest town to the property has both a tourist information center and a caravan park, then the property is considered to be situated near a tourist town (i.e. tourist town=1).

\section{Results}

After removing observations with missing values and outliers, we obtained a dataset with 35,942 observations. An OLS estimation of the HPP models of housing prices for models 1-3 was estimated

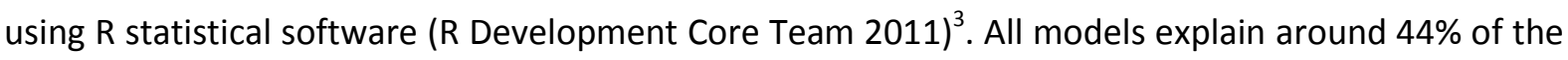
variation of the dependent variable.

The OLS models were tested for spatial dependencies. Moran's I statistic indicates a clustering pattern of the residuals. The Lagrange multiplier (LM) test (Anselin et al. 1996) indicates the presence of spatial error and spatial lag dependencies. However, the Robust LM test for spatial error dependency is statistically significant (Robust $L M=15188.15, p<0.0001$ ), while the Robust Lagrange multiplier test of spatial lag dependency is not (Robust $L M=0.02, p=0.8947$ ), suggesting that spatial error dependency is more prominent in this case ${ }^{4}$. Furthermore, caution should be exercised when interpreting these results for spatial lag, because this test does not take into account the temporal component (Maddison 2009). Therefore, we estimate a spatial error HPP model.

\subsection{Spatial regression estimation}

Results of estimating spatial error HPP models 1-3 are presented in top section of Table 2. As expected, spatial error coefficient is positive and significant confirming the presence of positive spatial error relationships across all three models. Signs of the coefficient in spatial model are consistent with the signs in the OLS model; however magnitudes of the coefficients and standard errors differ in places, especially for the variables derived from geographic data or for the distance based variables. In the following we will discuss coefficients estimated spatial error model.

\footnotetext{
${ }^{2}$ Data on tourism was obtained from the website http://www.planetware.com/towns/australia-cities-towns-scenicregions-aus.htm, and data on caravan parks was obtained from the website http://www.goseeaustralia.com.au/caravanparkspage.asp.

${ }^{3}$ OLS results can be provided upon request to the authors.

${ }^{4}$ Test of spatial autocorrelation results can be provided upon request to the authors.
} 
Table 2. Spatial model regression results

\begin{tabular}{|c|c|c|c|}
\hline Variables & $\begin{array}{c}\text { Model } 1 \\
\text { Nearest site }\end{array}$ & $\begin{array}{c}\text { Model } 2 \\
\text { Weighted distance to } \\
\text { the sites }\end{array}$ & $\begin{array}{c}\text { Model } 3 \\
\text { Separate sites }\end{array}$ \\
\hline Intercept & $5.60570 \ddagger(0.30190)$ & $5.45640 \ddagger(0.28023)$ & $5.03330 \ddagger(0.34704)$ \\
\hline $\log \left(\right.$ Property area, $\left.\mathrm{m}^{2}\right)$ & $0.15577 \ddagger(0.00389)$ & $0.15613 \ddagger(0.00389)$ & $0.15947 \ddagger(0.00389)$ \\
\hline Number of bedrooms & $0.31228 \ddagger(0.01486)$ & $0.31287 \ddagger(0.01486)$ & $0.31107 \ddagger(0.01485)$ \\
\hline Number of bedrooms, squared & $-0.02201 \ddagger(0.00216)$ & $-0.02206 \ddagger(0.00216)$ & $-0.02187 \ddagger(0.00216)$ \\
\hline Agricultural land use & $-0.08567 \ddagger(0.01474)$ & $-0.08760 \ddagger(0.01473)$ & $-0.08582 \ddagger(0.01466)$ \\
\hline Tourist town & $0.13288 \ddagger(0.01151)$ & $0.14203 \ddagger(0.01127)$ & $0.09785 \ddagger(0.01213)$ \\
\hline $\log (P G I)$ & $0.28875 \ddagger(0.02574)$ & $0.30974 \ddagger(0.02385)$ & $0.33061 \mp(0.02857)$ \\
\hline Dist to town, $\mathrm{km}$ & $0.00929 \ddagger(0.00281)$ & $0.00957 \ddagger(0.00278)$ & $0.00724 \ddagger(0.00281)$ \\
\hline Dist to town, $\mathrm{km}$, squared & $-0.00100 \ddagger(0.00011)$ & $-0.00099 \ddagger(0.00011)$ & $-0.00092 \ddagger(0.00011)$ \\
\hline $\log ($ Dist to nearest KEA, $\mathrm{km})$ & $-0.03654 \ddagger(0.00733)$ & - & - \\
\hline Log(Wdist to 3 KEAs km) & - & $-0.05958 \ddagger(0.01003)$ & - \\
\hline Log(Dist to BMF, km) & - & - & $-0.07402 \ddagger(0.01120)$ \\
\hline Log(Dist to GKPF, km) & - & - & $0.00130(0.00971)$ \\
\hline Log(Dist to LGFP, km) & - & - & $-0.04807 \ddagger(0.00812)$ \\
\hline Log(Dist to the Nearest NP, km) & $-0.00117(0.00514)$ & - & - \\
\hline $\log ($ Wdist to NP, km) & - & $-0.00161(0.00551)$ & - \\
\hline Log(Dist to Bendigo NP, km) & - & - & $-0.02829 \ddagger(0.00555)$ \\
\hline $\log ($ Dist to $H-G N P, k m)$ & - & - & $0.10598 \ddagger(0.01086)$ \\
\hline Log(Dist to river, $\mathrm{km}$ ) & $-0.04355 \ddagger(0.00690)$ & $-0.03901 \ddagger(0.00687)$ & $-0.03936 \ddagger(0.00697)$ \\
\hline Log(Area of/dist to NCA, ha/km) & $0.01107 \ddagger(0.00151)$ & $0.01147 \ddagger(0.00150)$ & $0.01407 \ddagger(0.00149)$ \\
\hline NDVI & $0.00004 \ddagger(0.00000)$ & $0.00005 \ddagger(0.00000)$ & $0.00005 \ddagger(0.00000)$ \\
\hline Elevation, $\mathrm{m}$ & $0.00076 \ddagger(0.00018)$ & $0.00066 \ddagger(0.00016)$ & $0.00128 \ddagger(0.00019)$ \\
\hline Month & $-0.01336 \ddagger(0.00260)$ & $-0.01332 \ddagger(0.00260)$ & $-0.01313 \ddagger(0.00260)$ \\
\hline Month squared & $0.00072 \ddagger(0.00019)$ & $0.00071 \ddagger(0.00019)$ & $0.00070 \ddagger(0.00019)$ \\
\hline Trend, years & $0.25025 \ddagger(0.00341)$ & $0.25133 \ddagger(0.00341)$ & $0.25072 \ddagger(0.00341)$ \\
\hline Trend, years, squared & $-0.01194 \ddagger(0.00026)$ & $-0.01203 \ddagger(0.00026)$ & $-0.01200 \ddagger(0.00027)$ \\
\hline Spatial error & $0.59552 \ddagger(0.00556)$ & $0.59474 \ddagger(0.00540)$ & $0.58414 \ddagger(0.00567)$ \\
\hline $\mathrm{N}$ & 35,942 & 35,942 & 35,942 \\
\hline AIC & 35,575 & 35,756 & 35,742 \\
\hline Note: & $\begin{array}{l}\text { eses, * Significant a } \\
\text { KEA=Key Environme } \\
\text { Perricoota Forest, LC } \\
\text { =National park, H-G } \\
\text { zed Difference Ve }\end{array}$ & $\begin{array}{l}\text { \% level; }+ \text { significant a } \\
\text { Asset, BMF=Barmah } \\
\text { LowerGoulburn Flooc } \\
\text { thcote-Graytown, NC } \\
\text { tion Index during } 12\end{array}$ & $\begin{array}{l}\text { level; ¥ significant a } \\
\text { lewa Forest, } \\
\text { n, Dist=Distance, } \\
\text { Jature conservation } \\
\text { nths prior to sale }\end{array}$ \\
\hline
\end{tabular}




\subsubsection{General results}

Before discussing the KEA variables, we first address the structural and neighbourhood variables to confirm that the results are consistent with our hypothesis. The coefficients of the log of property area and number of bedrooms are positive and highly significant. Negative coefficient for the squared term of number of bedrooms indicates diminishing return to the size of the house represented by the number of rooms. Properties classified as agricultural lands have lower value than properties classified as residential land. The PGI, a measure of population and market access positively influences property values. This confirms our expectation that proximity to and size of populated places drives demand for residential properties, if the nearest town is tourist town it will have a positive effect on sales value. The significant linear and squared term for the month and trend variable confirms seasonal fluctuations of sales price as well as the growth of sales prices that is beyond inflation. The average NDVI during the 12 months prior to sale data has a positive effect on property sales price confirming our expectations that neighbourhood greenness leads to higher prices. As expected also, elevation is significant and has a positive effect on sales price.

For the other environmental assets that are non KEAs, the natural log of distance to the river is negative, which also suggests the positive effect of being in close proximity to rivers on property prices. Size of the nearest conservation area divided by the distance is significant and positive across all three models suggesting a positive effect of conservation area and proximity on property price. The two NPs were only statistically significant when modelled as separate variables. The coefficient of log distance to Bendigo NP is negative suggesting that there are price advantages to being in close proximity to this site. However, proximity to the Heathcote-Graytown NP negatively affects sales price. This finding is expected as the Bendigo NP has high amenity value, while the HeathcoteGraytown national park has less amenity value and is potentially a source of forest fire to the adjacent town.

\subsubsection{KEA results}

The parameter values of interest are the ones for the distance to the KEAs. Parameter estimates for model 1 , where the KEA proximity effect on property price is represented by the distance to the nearest KEA, the coefficient of the log distance to the KEAs is negative and significant as expected. The same relationship is found for model 2, where distance to the nearest KEA is calculated by using the weighted harmonic mean distance to all three KEAs. Moving onto model 3, where distance to the three KEAs are represented by three separate log distance variables, the parameter values indicate that the natural log of distance to the BMF is negative and significant at $p<0.01$. This relationship is expected and suggests that there is a positive effect of being in close proximity to the BMF. The coefficient of the log distance to the LGFP is negative and significant. Log distance to the GKPF, on the other hand, was not significant in the OLS model nor the spatial model. Therefore, the results suggest that there is no added value to property prices for being in close proximity to the GKPF. 


\subsection{KEA specification and impact on MIP}

Table 3 shows MIPs of the structural, neighbourhood and environmental attributes at the means of the property value and respective explanatory variable were calculated using coefficients estimated by a spatial error hedonic model. The MIP, or willingness to pay, is the value of the amenity capitalised in the residential property price, assuming that the property market is in equilibrium (Tapsuwan et al. 2009).

Table 3. Marginal implicit prices and elasticities of statistically significant variables

\begin{tabular}{lrr}
\hline Variable & MIP & Elasticity \\
\hline Property area, m2 & 11.74 & 0.16 \\
Number of bedrooms & 34,209 & 0.06 \\
Agricultural land use & $-16,640$ & -0.08 \\
Tourist town & 18,972 & 0.10 \\
Population gravity index & 0.61 & 0.33 \\
Distance to the nearest town, km & -56 & 0.00 \\
Distance to nearest KEA, km & -60 & -0.02 \\
Weighted distance to BMF,GKPF,LGFP, km & -190 & -0.08 \\
Distance to BMF, km & -166 & -0.07 \\
Distance to LGFP, km & -136 & -0.05 \\
Distance to Bendigo NP, km & -74 & -0.03 \\
Distance to Heathcote-Graytown NP, km & 285 & 0.11 \\
Distance to the nearest river, km & $-2,198$ & -0.04 \\
Area/distance of nearest conservation area, ha/km & 1.50 & 0.01 \\
Average NDVI during 12 month prior to sale & 9.10 & 0.25 \\
Elevation level, m & 249 & 0.22 \\
\hline Note: Both values are estimated at the mean of the sample & & \\
$\quad$ KEA=Key Environmental Asset, BMF=Barmah-Millewa Forest, GKPF=Gunbower-Koondrook-Perricoota
\end{tabular}

The manner in which the KEAs are specified results in different marginal changes to sales price relative to proximity. An average property in this data set is 2,635 square meters, has 3 bedrooms, is valued at $\$ 194,000$, and is on average $82 \mathrm{~km}$ away from all three KEAs. Following the traditional method of estimating distance to the nearest KEA (model 1), for an average property, moving $1 \mathrm{~km}$ north from its current location, would increase property price by $\$ 99$. However, if the distance variable was based on the mean harmonic weighted distance to all three KEAs (following model 2), then moving $1 \mathrm{~km}$ north will increase property price by around \$207. Although two values are quite different they are not comparable because of the manner in which the proximity variable is calculated. In the case of the mean harmonic weighted distance, moving $1 \mathrm{~km}$ closer might not change the value of the weighted distance variable by exactly $1 \mathrm{~km}$ (because the property might then be moving away from another KEA at the same time).

In any case, both methods (following model 1 and model 2) do not offer much information as to which site is valued more than the other. On the other hand, following model 3 , we are able to 
individually estimate that for an average property located at the mean distance of $100 \mathrm{~km}$ from the BMF, moving $1 \mathrm{~km}$ closer to BMF increases property price by $\$ 166$. For the LGFP, moving $1 \mathrm{~km}$ closer increases sales price by $\$ 74$. Proximity to the GKPF does not affect property value since the parameter value was not significantly different from zero.

\subsection{The Millennium Drought impact on KEAs}

To capture the effect of the Millennium Drought on the MIP of environmental assets, we estimated an additional spatial HPP model using the specification in model 3 by adding interaction terms to identify whether sales occurred during the drought or non-drought periods. Any sales transaction before 2010 was considered to occur during the drought period, while any transaction from 2010 onwards was considered to occur during the non-drought period. Table 4 presents results from the spatial model with values of KEAs estimated during and after the drought. Note that only the parameter values for the KEAs are presented in this table as other parameter values did not significantly change. Results suggest that the drought has a significant effect on only the values of the BMF and the LGFP. This outcome is expected as the parameter value for distance to the GKPF was not significant in either the OLS or spatial model. As such, the drought would have no effect on the parameter value of proximity to the GKPF. The MIPs for the BMF and the LGFP during the drought and non-drought periods are presented in the third column of Table 4. The MIPs for the BMF and the LGFP during the drought period are larger than the MIPs during the non-drought period. This suggest that during the dry years, the areas that are healthy, wet and green are scarce and proximity premium to these sites increases to reflect the scarcity of healthy looking places.

Table 4. Results of spatial model (with values of KEA estimated during and after the drought)

\begin{tabular}{lrrr}
\hline Variables & Coefficients and standard error & MIP & Elasticity \\
\hline $\log ($ Distance to $B M F, k m) *$ during drought & $-0.09426 \ddagger(0.01135)$ & -212 & -0.09 \\
$\log ($ Distance to $B M F, k m) *$ after drought & $-0.06106 \ddagger(0.01372)$ & -137 & -0.06 \\
$\log ($ Distance to LGFP, $\mathrm{km}) *$ during drought & $-0.04685 \ddagger(0.00818)$ & -133 & -0.05 \\
$\log ($ Distance to LGFP, $\mathrm{km}) *$ after drought & $-0.02672 \ddagger(0.00958)$ & -76 & -0.03 \\
\hline
\end{tabular}

\section{Conclusion}

This paper argues the importance of correctly specifying environmental assets in a HPP model. We proposed a method in which environmental assets are modelled as separate sites even though they fall under the same GIS classification. Specifically, we examined the effect of proximity to KEAs on sales price (through the estimation of MIPs). We specified proximity to KEAs in three manners: 1) as one variable where proximity is calculated only to the nearest site, 2) as one variable but is represented by the weighted harmonic mean distance to all three KEAs, and 3) as three separate variables representing the three separate sites. The results of this study suggest that proximity to only two out of the three sites significantly increases property sales price. Without the correct model specification, the results would suggest otherwise. Applying the same method to NPs, we arrive at 
the same conclusion that when environmental assets are modelled as separate sites, they produce different outcomes as to when they are represented by one variable. Therefore, without appropriate GIS classification and resources to invest in improving data quality, one can still differentiate the environmental asset by modelling them as individual sites, rather than assume that all sites of the same asset are homogenous. We do not argue that this is the ideal method, but is the best available method when data availability is limited.

The model results suggest that the MIP and significance level of the proximity is much stronger for the BMF than the LGFP. This finding is not surprising since the BMF is a major tourist attraction in the region, with approximately 100,000 visitor days per year. Tourists are drawn to the BMF because of its forest and river environment where activities such as bushwalking, bird watching, fishing, and camping can be performed (Murray-Darling Basin Commission 2005b). The consequence of modelling the effect of these three sites as one variable is inadvertently placing too much value on the LGFP and the GKPF, and placing too little value on the BMF. Only by modelling the effect of these three sites as separate variables do we discover that the BMF is the most valued KEA in the MDB.

The policy implication of this finding is that in times of drought when water resources are incredibly limited and environmental water flow is not sufficient to support all KEAs, the KEA that should be given priority to environmental water flow is the one that offers the highest value to the residents in the area. In the case of the MDB, it would be the BMF. As a consequence of having the right model specification, we are able to correctly inform decision making on prioritising environmental flow, rather than wasting valuable water resources trying to distribute environmental water flow to all three sites. We do recognise, however, that there are other environmental values and services, such as ecological values (i.e. the survival of key ecological species) that can override allocation decisions.

\section{References}

Anselin, L. 1988. Spatial Econometrics: Methods and Models: Springer.

Anselin, L., A. K. Bera, R. Florax, and M. J. Yoon. 1996. Simple diagnostic tests for spatial dependence. Regional Science and Urban Economics 26(1):77-104.

Bark, R. H., D. E. Osgood, B. G. Colby, and E. B. Halper. 2011. How do homebuyers value different types of green space? Journal of Agricultural and Resource Economics 36(2):395-415.

Bureau of Meteorology. 2014. Map Information - Normalised Difference Vegetation Index. Available from http://www.bom.gov.au/climate/austmaps/about-ndvi-maps.shtm [Accessed March 2014].

Conway, D., C. Q. Li, J. Wolch, C. Kahle, and M. Jerrett. 2010. A spatial autocorrelation approach for examining the effects of urban greenspace on residential property values. Journal of Real Estate Finance and Economics 41(2):150-169.

DEPI. 2010. A guide to the inland angling waters of Victoria: Goulburn River Basin. Department of Environment and Primary Industries, State Government of Victoria. Available from 
http://www.dpi.vic.gov.au/fisheries/recreational-fishing/inland-angling-guide/?a=12837 [Accessed April 2014].

Donovan, G. H., and D. T. Butry. 2010. Trees in the city: Valuing street trees in Portland, Oregon. Landsc. Urban Plan. 94(2):77-83.

ESRI. 2010. ArcGIS 10. Redlands, CA: Environmental Systems Research Institute.

Freeman, A. M. 2003. The Measurements of Environmental and Resource Values: Theory and Methods: RFF Press.

Freeman, M. A. 1974. On estimating air pollution control benefits from land value studies. Journal of Environmental Economics and Management 1(1):74-83.

Ham, C., P. A. Champ, J. B. Loomis, and R. M. Reich. 2012. Accounting for heterogeneity of public lands in hedonic property models. Land Econ. 88(3):444-456.

Hatton MacDonald, D., N. D. Crossman, P. Mahmoudi, L. O. Taylor, D. M. Summers, and P. C. Boxall. 2010. The value of public and private green spaces under water restrictions. Landsc. Urban Plan. 95(4):192-200.

Kim, C. W., T. T. Phipps, and L. Anselin. 2003. Measuring the benefits of air quality improvement: A spatial hedonic approach. Journal of Environmental Economics and Management 45(1):2439.

Kovacs, K., T. P. Holmes, J. E. Englin, and J. Alexander. 2011. The Dynamic Response of Housing Values to a Forest Invasive Disease: Evidence from a Sudden Oak Death Infestation. Environmental and Resource Economics 49(3):445-471.

Maddison, D. 2009. A Spatio-temporal Model of Farmland Values. J. Agric. Econ. 60(1):171-189.

Mahan, B. L., S. Polasky, and R. M. Adams. 2000. Valuing urban wetlands: A property price approach. Land Econ. 76(1):100-113.

Mansfield, C., S. K. Pattanayak, W. McDow, R. McDonald, and P. Halpin. 2005. Shades of Green: Measuring the value of urban forests in the housing market. Journal of Forest Economics 11(3):177-199.

MDBA. 2011. The proposed "environmentally sustainable level of take" for surface water of the Murray-Darling Basin: Method and Outcomes. Canberra: Murray-Darling Basin Authority. http://download.mdba.gov.au/proposed/ESLT_MDBA_report.pdf [accessed April 2013].

MDBA. 2012. Gunbower-Koondrook-Perricoota Forest [Online]. Available from http://www.mdba.gov.au/programs/tlm/icon_sites/gkp_forest [Accessed April 2012].

Murray-Darling Basin Commission. 2005a. Information base for the Gunbower and KoondrookPerricoota forests. The Living Murray Foundation Report on the significant ecological assets targeted in the First Step Decision.

Murray-Darling Basin Commission. 2005b. The Living Murray Foundation Report on the significant ecological assets targeted in the First Step Decision. Canberra: MDBC Publication No. 09/05. 
Payton, S., G. Lindsey, J. Wilson, J. R. Ottensmann, and J. Man. 2008. Valuing the benefits of the urban forest: a spatial hedonic approach. Journal of Environmental Planning and Management 51(6):717-736.

Polyakov, M., D. J. Pannell, R. Pandit, S. Tapsuwan, and G. Park. 2013. Valuing Environmental Assets on Rural Lifestyle Properties. Agricultural and Resource Economics Review 42(1):159-175.

Polyakov, M., and D. W. Zhang. 2008. Property tax policy and land-use change. Land Econ. 84(3):396408.

Powe, N. A., G. D. Garrod, C. F. Brunsdon, and K. G. Willis. 1997. Using a geographic information system to estimate an hedonic price model of the benefits of woodland access. Forestry 70(2):139-149.

R Development Core Team. 2011. R: A Language and Environment for Statistical Computing. Vienna, Austria: R Foundation for Statistical Computing.

Reserve Bank of Australia. 2012. Consumer price index - G2 Available from http://www.rba.gov.au/statistics/tables/\#prices_inflation [Accessed June 2012].

Rosen, S. 1974. Hedonic prices and implicit markets - product differentiation in pure competition. Journal of Political Economy 82(1):34-55.

Sander, H., S. Polasky, and R. G. Haight. 2010. The value of urban tree cover: A hedonic property price model in Ramsey and Dakota Counties, Minnesota, USA. Ecological Economics 69(8):1646-1656.

Sengupta, S., and D. E. Osgood. 2003. The value of remoteness: A hedonic estimation of ranchette prices. Ecological Economics 44(1):91-103.

Tapsuwan, S., G. Ingram, M. Burton, and D. Brennan. 2009. Capitalized amenity value of urban wetlands: a hedonic property price approach to urban wetlands in Perth, Western Australia. Australian Journal of Agricultural and Resource Economics 53(4):527-545.

Tapsuwan, S., D. H. MacDonald, D. King, and N. Poudyal. 2012. A combined site proximity and recreation index approach to value natural amenities: An example from a natural resource management region of Murray-Darling Basin. Journal of Environmental Management 94(1):69-77.

Taylor, L. 2003. The Hedonic Method. In A Primer on Nonmarket Valuation, ed. P. Champ, K. Boyle and T. Brown: Springer Netherlands.

Taylor, L. O. 2008. Theoretical foundations and empirical developments in hedonic modeling: Springer New York.

Tyrväinen, L., K. Mäkinen, and J. Schipperijn. 2007. Tools for mapping social values of urban woodlands and other green areas. Landsc. Urban Plan. 79(1):5-19. 